\title{
Patient-reported health-related quality of life after a displaced intra-articular calcaneal fracture: a systematic review
}

\author{
G. Alexandridis*, A. C. Gunning and L. P. H. Leenen
}

\begin{abstract}
Background: A displaced intra-articular calcaneal fracture (DIACF) is known for having a negative influence on the daily activities of patients. A health-related quality of life (HRQoL) outcome instrument is used to quantify the impact of DIACF. It seems that these studies used restrictive inclusion criteria and observe specific patient groups; consequently, an increased risk of bias that results in incorrect estimation of the impact. Therefore, we will systematically review the current literature.

Materials and methods: A systematic search was performed in PubMed, Embase and Cochrane library. Inclusion criteria were studies reporting DIACF and HRQoL, measured with SF-36, SF-36v2, EQ-5D or EQ-6D. The identified articles were critically appraised for their relevance and validity. The overall risk of bias was determined. The studies with a low to medium risk of bias were used for data extraction.

Results: 32 articles were available for the critical appraisal. 13 articles had a medium risk of bias. All studies reported the SF-36 and two studies also reported the EQ-5D.

Conclusions: This systematic review indicates that DIACF is a life-changing event for most patients. The HRQoL is substantially lower in comparison to the period before the trauma and to the general population, in particular the subdomains related to the physical domain are affected. In addition, this review reveals that the identified studies have a medium to high risk of bias. Consequently, it is challenging to make reliable and valid conclusions. Therefore, we provided recommendations to decrease the risk of bias in order to improve future research.
\end{abstract}

Keywords: Displaced intra-articular calcaneal fracture, Systematic review, Quality of life, Long-term follow up, SF-36, EQ-5D

\section{Background}

It is well-known among orthopedic healthcare providers that a displaced intra-articular calcaneal fracture (DIACF) has a negative influence on the daily activities of patients and affects their quality of life substantially $[1,2]$. Moreover, this fracture has an adverse economic impact on society. Buckley et al. [1] showed that approximately $20 \%$ of these patients do not return to work after 1 year.

A health-related quality of life (HRQoL) outcome instrument is used to quantify the impact of a DIACF on the daily activities of these patients [1, 3-8]. Policy makers

\footnotetext{
* Correspondence: georgios.alexandridis@gmail.com Department of Surgery, University Medical Center Utrecht, Suite: G04.228Heidelberglaan 100, 3584 CX Utrecht, The Netherlands
}

use these HRQoL outcomes for economic assessments and to optimize the use of the scarce resources. Improving HRQoL might result in an increased number of patients who return to work, and consequently this will increase the cost-effectiveness of the management of patients with a DIACF.

In current literature studies were performed that use HRQoL as outcome. These studies demonstrated to have lower HRQoL scores in comparison to the general population $[1,7,8]$. However, these studies tend to use restrictive inclusion criteria and to observe specific patient groups [1, 6-8]. As a consequence, these studies are prone to provide results that seem too positive to us, and might underestimate the need for advancements of 
research to improve the daily lives of patients with a DIACF.

Previous systematic reviews have reported HRQoL on DIACF, but focused mainly on comparing treatments with outcomes such as complications, return to work rate, or the ability to wear certain shoes. As a result, these reviews have not included all the available original studies on HRQoL after a DIACF; subsequently, this may bias the HRQoL outcome after a DIACF [9-17].

Therefore, a thoroughly and explicit assessment of the validity of primary studies that use HRQoL as an outcome is required. With this knowledge, more insight in the disease specific progression could be established and the rehabilitation process could be improved.

This is the first systematic review, which focuses solely on the HRQoL in adult patients who sustained a traumatic DIACF. We will critically appraise the validity of current literature. As a result, we will present a comprehensive overview of the quality of these studies and provide a thorough update on the best available evidence of the HRQoL status in patients with a DIACF.

\section{Review}

\section{Introduction}

It is well-known among orthopedic healthcare providers that a displaced intra-articular calcaneal fracture (DIACF) has a negative influence on the daily activities of patients and affects their quality of life substantially $[1,2]$. Moreover, this fracture has an adverse economic impact on society. Buckley et al. [1] showed that approximately $20 \%$ of these patients do not return to work after 1 year.

A health-related quality of life (HRQoL) outcome instrument is used to quantify the impact of a DIACF on the daily activities of these patients [1,3-8]. Policy makers use these HRQoL outcomes for economic assessments and to optimize the use of the scarce resources. Improving HRQoL might result in an increased number of patients who return to work, and consequently this will increase the cost-effectiveness of the management of patients with a DIACF.

In current literature studies were performed that use HRQoL as outcome. These studies demonstrated to have lower HRQoL scores in comparison to the general population $[1,7,8]$. However, these studies tend to use restrictive inclusion criteria and to observe specific patient groups $[1,6-8]$. As a consequence, these studies are prone to provide results that seem too positive to us, and might underestimate the need for advancements of research to improve the daily lives of patients with a DIACF.

Previous systematic reviews have reported HRQoL on DIACF, but focused mainly on comparing treatments with outcomes such as complications, return to work rate, or the ability to wear certain shoes. As a result, these reviews have not included all the available original studies on HRQoL after a DIACF; subsequently, this may bias the HRQoL outcome after a DIACF [9-17].

Therefore, a thoroughly and explicit assessment of the validity of primary studies that use HRQoL as an outcome is required. With this knowledge, more insight in the disease specific progression could be established and the rehabilitation process could be improved.

This is the first systematic review, which focuses solely on the HRQoL in adult patients who sustained a traumatic DIACF. We will critically appraise the validity of current literature. As a result, we will present a comprehensive overview of the quality of these studies and provide a thorough update on the best available evidence of the HRQoL status in patients with a DIACF.

\section{Materials and methods}

The Preferred Reporting Items for Systematic Reviews and Meta-Analyses (PRISMA) guideline was used to conduct this review [18].

\section{Health-related quality of life (HRQoL)}

HRQoL is the subjective evaluation of the aspects that affect a person's health. These aspects are classified into the physical, psychological, and social domain. These domains can be further specified into subdomains. Pain and physical functioning are subdomains of the physical domain. The psychological domain is further specified in emotional and mental health. The quality of social contacts and behavior are subdomains of the social domain.

For the assessment of HRQoL, several instruments have been developed and validated, such as the Medical Outcomes Study 36-item Short Form Health Survey (SF-36) and the EuroQol 5D (EQ-5D) [19-22]. There is, to our knowledge, no validated patient reported outcome which specifically addresses patients with a DIACF or patients with an ankle or foot disorder. The literature states that SF-36 can be used as a valid instrument to measure HRQoL in these patients [3-5].

\section{Search strategy}

A computerized search was conducted on March 15, 2015 in the search engines PubMed, Cochrane library and Embase. The search syntax encompassed calcaneus, fracture, and the outcome instruments: SF-36, SF-36v2, $E Q-5 D$ and $E Q-6 D$ (including their respective synonyms) [19-22]. Table 1 contains an overview of the complete search syntax. We searched titles and abstracts. All articles, which met the search terms, were exported from the search engines to Reference Manager version 12.0.

\section{Selection}

Our aim was to analyze all articles evaluating the HRQoL in patients with DIACF; therefore, we have 
Table 1 Search syntax per search engine. Search conducted on 15th March of 2015

\section{PubMed:}

(calcaneus[tiab] OR calcaneum[tiab] OR calcaneal[tiab] OR calcis[tiab] OR kalkaneus[tiab] OR (heel[tiab] AND bone[tiab]) OR fersenbein[tiab] OR hielbeen[tiab] OR hielbot[tiab] OR calcanean[tiab] OR calcanea[tiab]) AND (fracture[tiab] OR fractures[tiab] OR lesion[tiab] OR lesions[tiab] OR broken[tiab] OR fractured[tiab] OR splintered[tiab] OR displaced[tiab] OR displacement[tiab] OR discontinuity[tiab] OR discontinuities[tiab] OR gebroken[tiab] OR fracture[tiab] OR frakturen[tiab] OR fractuur[tiab] OR fracturen[tiab] OR fragmentation[tiab] OR fragmented[tiab] OR fragment[tiab] OR cleavage[tiab] OR cleavages[tiab]) AND (sf36[tiab] OR sf-36[tiab] OR (sf[tiab] AND 36[tiab]) OR (health[tiab] AND (survey[tiab] OR surveys[tiab] OR review[tiab] OR reviews[tiab] OR questionnaire[tiab] OR questionnaires[tiab])) OR (short[tiab] AND (form[tiab] OR form-36[tiab])) OR short-form[tiab] OR euroqol[tiab] OR euroqol-5[tiab] OR euroqol-6[tiab] OR eq-5d[tiab] OR eq-6d[tiab] OR (quality[tiab] AND life[tiab]) OR ((clinical[tiab] OR functional[tiab]) AND (assessment[tiab] OR score[tiab] OR scores[tiab] OR outcome[tiab] OR outcomes[tiab])))

Embase:

calcaneus:ab,ti OR calcaneum:ab,ti OR calcaneal:ab,ti OR calcis:ab,ti OR kalkaneus:ab,ti OR (heel:ab,ti AND bone:ab,ti) OR fersenbein:ab,ti OR hielbeen:ab,ti OR hielbot:ab,ti OR calcanean:ab,ti OR calcanea:ab,ti AND (fractures:ab,ti OR lesion:ab,ti OR lesions:ab,ti OR broken:ab,ti OR fractured:ab,ti OR splintered:ab,ti OR displaced:ab,ti OR displacement:ab,ti OR discontinuity:ab,ti OR discontinuities:ab,ti OR gebroken:ab,ti OR fracture:ab,ti OR frakturen:ab,ti OR fractuur:ab,ti OR fracturen:ab,ti OR fragmentation:ab,ti OR fragmented:ab,ti OR fragment:ab,ti OR cleavage:ab,ti OR cleavages:ab,ti) AND (sf36:ab,ti OR 'sf 36':ab,ti OR (sf:ab,ti AND 36:ab,ti) OR (health:ab,ti AND (survey:ab,ti OR surveys:ab,ti OR review:ab,ti OR reviews:ab,ti OR questionnaire:ab,ti OR questionnaires:ab,ti)) OR (short:ab,ti AND (form:ab,ti OR 'form 36':ab,ti)) OR 'short form':ab,ti OR euroqol:ab,ti OR 'euroqol 5':ab,ti OR 'euroqol 6':ab,ti OR 'eq 5d'ab,ti OR 'eq 6d'ab,ti OR (quality:ab,ti AND life:ab,ti) OR (clinical:ab,ti OR functional:ab,ti AND (assessment:ab,ti OR score:ab,ti OR scores:ab,ti OR outcome:ab,ti OR outcomes:ab,ti)))

Cochrane Library: searched in title, abstract and keywords

(calcaneus OR calcaneum OR calcaneal OR calcis OR kalkaneus OR (heel AND bone) OR fersenbein OR hielbeen OR hielbot OR calcanean OR calcanea) AND (fracture OR fractures OR lesion OR lesions OR broken OR fractured OR splintered OR displaced OR displacement OR discontinuity OR discontinuities OR gebroken OR fracture OR frakturen OR fractuur OR fracturen OR fragmentation OR fragmented OR fragment OR cleavage OR cleavages) AND (sf36 OR sf-36 OR (sf AND 36) OR (health AND (survey OR surveys OR review OR reviews OR questionnaire $O R$ questionnaires)) OR (short AND (form OR form-36)) OR short-form OR euroqol OR euroqol-5 OR euroqol-6 OR eq-5d OR eq-6d OR (quality AND life) OR ((clinical OR functional) AND (assessment OR score OR scores OR outcome OR outcomes)))

included all articles written in English, German, French or Dutch that assessed patients who had a primary treated DIACF and reported results of SF-36, SF-36v2, EQ-5D, or EQ-6D.

At first, all duplicates were excluded. The titles and abstracts of the articles were screened by one reviewer (GA), based on the inclusion criteria (Fig. 1). We have excluded articles that assessed patients who were aged younger than 16 years. In addition, we excluded articles that are reviews. The full text of the remaining articles was screened by two reviewers (GA, ACG). From these articles and the identified systematic reviews, all references were screened using the same criteria. In case of overlapping patient data, the article with the highest number of patients was included.

\section{Critical appraisal}

Predefined criteria were used for the assessment of validity and relevance in the selected articles; these criteria are presented in Table 2. Relevance concerned the applicability of the study findings to adult patients who sustained a DIACF. The preference was to use calcaneal fracture classification to determine intra- versus extra-articular fractures. In case a calcaneal fracture classification was not reported, we used the population criteria whether there were patients with intra- and extra-articular calcaneal fractures included.

Validity assessment established the extent of selection and information bias. For the assessment of the risk of bias we used the criteria for a prognostic study design from the Centre for Evidence Based Medicine of the University of Oxford, and criteria used in previous systematic reviews, which addressed HRQoL [23-26]. Two reviewers (GA, ACG) appraised the identified articles separately. In case of a difference in the critical appraisal of the selected articles between the two reviewers (GA, ACG), consensus was reached through discussion or a third reviewer (LPHL) was asked.

We developed a scoring system to determine the overall methodological quality of the studies, due to the large heterogeneity in the designs of the studies. As presented in the literature, priority criteria which are likely to be essential for the methodological quality have the highest weight in our scoring system [26]. Description of population characteristics is important for the interpretation of the results; it is generally accepted that the type of fracture and the length of follow-up have a substantial influence on the outcome $[27,28]$. Nevertheless, as described in the Cochrane Handbook for Systematic Reviews of Interventions, we did not value the transparency of methodology and reporting of population characteristics, because it is an uncertainty in the assessment of the risk of bias [29].

Eventually, we assigned points for each 'validity' criterion (Table 2 demonstrated the scores per criterion). Afterwards, we summed all these points per study (possible range -3 to 18 points). The total points of the studies were separated in three levels: high $(-3$ to 9 points), medium (10 to 13 points) or low risk of bias (14 to 18 points). Only articles with a low or medium risk of bias will be included in this systematic review and used for data extraction.

\section{Data extraction}

The SF-36 and SF-36v2 score ranges from 0 to 100 per subdomain; the higher the score the better the outcome [21, 22]. These instruments measure HRQoL across eight subdomains. The subdomain 'physical 


\section{calcaneus AND fracture AND HRQoL instrument}

Search performed on $15^{\text {th }}$ of March 2015

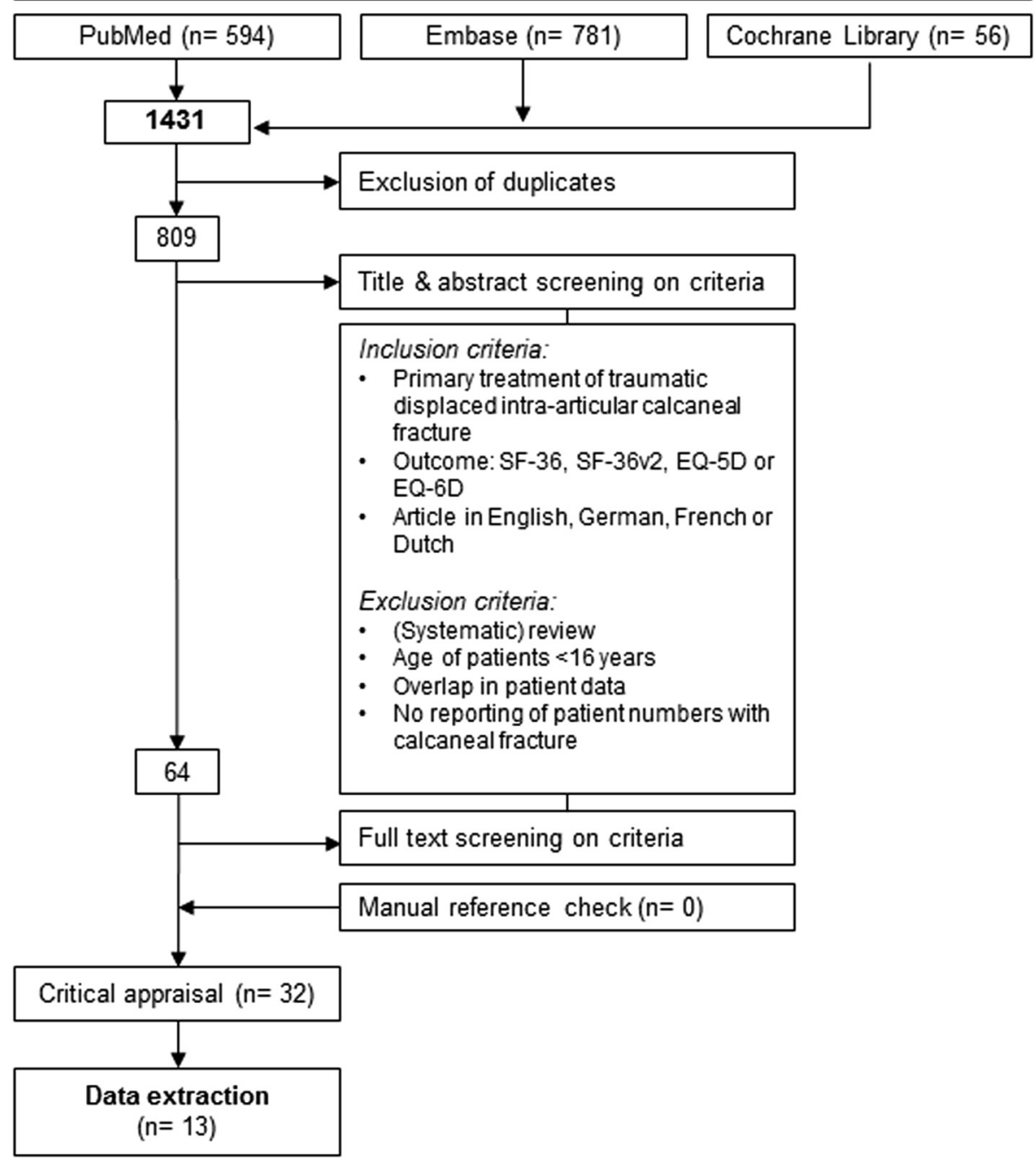

Fig. 1 Flow-chart of search strategy and selection

functioning' scores the performance of physical activities, 'role-physical' grades the limitations in daily activities as a result of physical health, and 'bodily pain' assesses the restrictions due to pain. 'General health' evaluates personal health, and 'vitality' measures energy and fatigue. 'Social functioning' is the subdomain score for interference due to emotional and physical problems with normal social activities. The 'role-emotional' subdomain measures the problems of daily activities as a result of emotional problems, and 'mental health' determines the psychological distress and well-being. These subdomains can be reduced to a 'physical component summary' (PCS) and a 'mental component summary' (MCS) score [21, 22].

The SF-36 and SF-36v2 have some differences in response choices, questions and in the calculation of the scores; the scores of the SF-36 and the SF-36v2 are comparable and can be combined [21, 22, 30].

The index score for EQ-5D ranges from below zero to one. A score of 1.00 is the highest possible score and indicates a patient who experiences no limitations in any of the subdomains, 0 indicates a HRQoL comparable to death, and a value below zero indicates a HRQoL worse than death [20].

We preferred to extract mean scores with standard deviation per subdomain. If these data were not available, we have calculated this data from the data presented in the studies. All data per group in the study were summed to calculate one overall mean score. In case we were not able to calculate mean scores from the presented data, we have contacted the authors by e-mail or telephone to ask for these data. 
Table 2 Legend by Table 2: critical appraisal

\begin{tabular}{|c|c|c|c|}
\hline \multirow[t]{3}{*}{ Study design } & + & \multicolumn{2}{|l|}{ Prospective study or randomized controlled trial } \\
\hline & \pm & \multicolumn{2}{|l|}{ Retrospective study } \\
\hline & - & \multicolumn{2}{|l|}{ Other, such as case report } \\
\hline \multicolumn{4}{|l|}{ Relevance } \\
\hline \multirow[t]{3}{*}{ Domain } & + & \multicolumn{2}{|l|}{ Studies including adult trauma patients with DIACF } \\
\hline & \pm & \multicolumn{2}{|l|}{$\begin{array}{l}\text { Studies including adult trauma patients } \\
\text { with other calcaneal fractures }\end{array}$} \\
\hline & - & \multicolumn{2}{|l|}{$\begin{array}{l}\text { Studies including adult trauma patients with } \\
\text { other solitary non-calcaneal fractures }\end{array}$} \\
\hline \multirow[t]{2}{*}{ Outcome } & + & \multicolumn{2}{|l|}{ SF-36, SF-26v2, EQ-5D or EQ-6D } \\
\hline & - & \multicolumn{2}{|l|}{ Other } \\
\hline Validity & & & Points \\
\hline \multirow[t]{2}{*}{ Transparency of methodology } & + & Clearly described methodology & - \\
\hline & - & Not clearly described methodology or not reported & - \\
\hline \multirow{2}{*}{$\begin{array}{l}\text { Characteristics of study population } \\
\text { (age, classification of calcaneal fracture, } \\
\text { length of follow-up, and associated injuries) }\end{array}$} & + & $\begin{array}{l}\text { Clearly described study population characteristics } \\
\text { and inclusion of all characteristics }\end{array}$ & - \\
\hline & - & $\begin{array}{l}\text { Not clearly described study population } \\
\text { characteristics or missing description of characteristics }\end{array}$ & - \\
\hline \multirow[t]{3}{*}{ Minimal selection bias } & + & All eligible patients included in the study population & +5 \\
\hline & \pm & Pre-selected patient groups or subgroups & +3 \\
\hline & - & Subjective selection of eligible patients or not reported & -3 \\
\hline \multirow[t]{3}{*}{ Outcome assessment } & + & $\begin{array}{l}\text { Complete mean crude scores per subdomain } \\
\text { in patient group, or crude scores per subdomain }\end{array}$ & +6 \\
\hline & \pm & $\begin{array}{l}\text { Incomplete mean crude scores per subdomain, } \\
\text { or mean cumulative scores or EQ-5D index scores }\end{array}$ & +4 \\
\hline & - & $\begin{array}{l}\text { No subdivision of the mean total scores in } \\
\text { the subdomains or cumulative scores }\end{array}$ & 0 \\
\hline \multirow[t]{3}{*}{ Lost to follow-up } & + & $<15 \%$ & +4 \\
\hline & \pm & 15 to $25 \%$ & +2 \\
\hline & - & $>25 \%$ or not reported & 0 \\
\hline \multirow[t]{2}{*}{ Missing data } & + & $\begin{array}{l}\text { Description of patient characteristics } \\
\text { who are lost to follow-up and how the } \\
\text { missing data was handled }\end{array}$ & +1 \\
\hline & - & $\begin{array}{l}\text { No description of patient characteristics } \\
\text { who are lost to follow-up or how missing } \\
\text { data was handled }\end{array}$ & 0 \\
\hline \multirow{3}{*}{$\begin{array}{l}\text { Standardization of the } \\
\text { conduction of the questionnaires }\end{array}$} & + & Standardized & +2 \\
\hline & - & Not standardized or not reported & 0 \\
\hline & & & Total points \\
\hline \multirow[t]{3}{*}{ Overall risk of bias } & + & Low risk of bias & 14 to 18 \\
\hline & \pm & Medium risk of bias & 10 to 13 \\
\hline & - & High risk of bias & -3 to 9 \\
\hline
\end{tabular}

In order to present the development of the HRQoL through the years, we have reported the results in order of mean follow-up time. If possible, the data of the studies will be pooled to calculate the mean scores per subdomain. The homogeneity of the articles will be determined with eyeballing [31].

\section{Results}

Search strategy \& selection

The search resulted in 1431 articles. First of all, we have excluded the duplicates, as a result 810 articles remained. Title and abstract screening was performed using predefined inclusion criteria, 64 articles were left for full text and 
reference screening. No additional articles were identified during the reference check. Sixteen articles had overlap in patient data. Eventually, 32 articles were available for the critical appraisal $[6-8,27,28,32-58]$. The flowchart is presented in Fig. 1.

\section{Critical appraisal}

An overview of the critical appraisal is presented in Table 3. Prior to critical appraisement, the authors of 24 articles were contacted for the necessary data $[6-8,28$, 32-36, 39-41, 43-45, 47-52, 55, 58]. Only De Groot et al. [48] provided their study data, and gave permission to present their data in this review.

Ten of the 32 articles have a prospective study design [7, 38, 39, 41, 44, 47, 52, 53, 56, 58]. Five articles did not entirely fulfill the criteria for relevance; these studies included non-displaced calcaneal fractures or other foot/ ankle fractures [36, 42, 49, 52, 57]. The majority of the articles did not provide all the patient characteristics of the population they have studied $[7,27,28,32-34$, $37,38,40,44-54]$. In the greater proportion of these studies, the associated injuries were not clearly described $[7,27,28,33,34,37,38,40,42,43,47-51,53,54,56-58]$. Several studies did not report the classification of calcaneal fracture [7, 27, 32, 33, 48, 49, 52].

Four of the 32 articles have a minimal selection bias [33, 38, 40, 51]. The other studies excluded specific patient groups, such as patients with open fractures, concomitant injuries, primary or secondary subtalar arthrodesis, systemic comorbidities or bilateral fractures. Furthermore, some studies only included one specific patient group with DIACF, e.g. solely patients with open fractures or one specific treatment $[45,53]$.

The complete mean crude scores per subdomain were presented in seven $[7,8,37,38,41,42,46]$; the other articles provided cumulative scores or did not report all the scores per subdomain. Ten articles provided a 'total' of SF-36 scores, which represents the mean score of all the eight subdomains of the SF-36 [28, 32, 34, 36, 39, 43, $44,49,50,54]$.

Seven articles had a follow-up rate above $85 \%[6,8$, $32-34,42,45]$. Five articles did not present any followup data $[41,44,49,52,54]$.

The authors of four studies presented data of patients who were lost to follow up [39, 55, 56, 58].

In 13 studies the inclusion of patients and the collection of patient data were not standardized or this information was not described in the studies $[8,27,32-34,38-40,42$, $44,45,51-53]$.

After the critical appraisal, 13 articles were scored with a medium risk of bias and were selected for the data extraction, none of the articles had a low risk of bias $[6-8,33,38,41,45,46,48,53,55,56,58]$.

\section{Data extraction}

The results of the data extraction are presented in Table 4 .

Patient characteristics All studies, except two, had a number of patients which ranged from 15 to 78 [7, 56]. The number of patients in the study of van Tetering et al. [7] and Griffin et al. [56] was 312 and 116 patients respectively.

Mean age of the patients in the studies ranged from 36 to 60 years. Van Tetering et al. [7] only provided the range of age (25 to 64 years), and Brunner et al. [46] did not present any data about the age of the patients in their study. All studies evaluated operatively treated.

Longer follow-up time, Makki et al. patients; the studies of Van Tetering et al. [7], Griffin et al. [56] and de Boer et al. [55] also included non-operatively treated patients.

Fracture characteristics Ten studies reported the classification of the type of calcaneal fracture, nine according to the Sanders classification, of which two also presented the Essex-Lopresti classification [6, 8, 38, 41, 45, 53, 55, 56, 58]. One study used the Orthopaedic Trauma Association (OTA) classification [46]. Three studies also reported the associated injuries of the studied population $[41,47,55]$.

Follow-up time In eleven studies the mean follow-up time ranged from 12 to 78 months $[7,8,33,38,41,45$, $46,48,53,55,56]$. Two studies had a substantial (2004) had a mean follow-up time of 120 months and Sanders et al. [58] 181 months [6].

HRQoL Ten studies used the SF-36 and three studies used the updated version, SF-36v2. Moreover, the studies of Griffin et al. [56] and De Boer et al. [55] also reported the mean EQ-5D index score. Six studies presented the SF-36 results for all the subdomains [7, 8, 38, 41, 46, 48]. In one study the results are presented graphically; the numerical values were obtained from this graph [41]. In seven studies we have calculated the mean scores from the results in the study $[6,7,38,41,45,48,58]$.

In the majority of the studies the SF-36 subdomain scores were similar. Several studies showed to be outliers in some subdomains. In the subdomain 'physical functioning' Heffernan et al. [33] and Beltran et al. [45] scored respectively the highest (83) and the lowest (40) score. The 'bodily pain' score was remarkably higher for Heffernan et al. [33] and De Groot et al. [48] which measured mean scores of respectively 84 and 71 . Beltran et al. [45] showed to have a lower score of 43 in 'social functioning'. The mean score of Brunner et al. [46] scored exceptionally lower in 'mental health' with a mean score of 41.

Beltran et al. [45] had the lowest scores in almost all the subdomains, in contrast to the study of Heffernan et al. [33] which had the highest scores in their reported subdomains 'physical functioning' and 'bodily pain'. Brunner et al. [46] 
Table 3 Critical appraisal (see Table 2 for the legend)

\begin{tabular}{|c|c|c|c|c|c|c|c|c|c|c|c|}
\hline & \multirow[b]{2}{*}{$\begin{array}{l}\text { Study } \\
\text { design }\end{array}$} & \multicolumn{2}{|c|}{ Relevance } & \multicolumn{7}{|l|}{ Validity } & \multirow[b]{2}{*}{$\begin{array}{l}\text { Risk of } \\
\text { Bias }\end{array}$} \\
\hline & & Domain & Outcome & $\begin{array}{l}\text { Transparency of } \\
\text { methodology }\end{array}$ & $\begin{array}{l}\text { Characteristics } \\
\text { of population }\end{array}$ & $\begin{array}{l}\text { Minimal } \\
\text { selection } \\
\text { bias }\end{array}$ & $\begin{array}{l}\text { Outcome } \\
\text { assessment }\end{array}$ & $\begin{array}{l}\text { Lost to } \\
\text { follow-up }\end{array}$ & $\begin{array}{l}\text { Missing } \\
\text { data }\end{array}$ & $\begin{array}{l}\text { Standardization } \\
\text { of conduction }\end{array}$ & \\
\hline $\begin{array}{l}\text { Hildebrand } \\
\text { (1996) [32] }\end{array}$ & RCS & + & + & + & - & - & - & + & NA & - & - \\
\hline $\begin{array}{l}\text { Heffernan } \\
\text { (2000) [33] }\end{array}$ & RCS & + & + & - & - & + & \pm & + & - & - & \pm \\
\hline $\begin{array}{l}\text { Kennedy } \\
\text { (2003) [34] }\end{array}$ & RCS & + & + & - & - & - & - & + & NA & - & - \\
\hline $\begin{array}{l}\text { Berry (2004) } \\
\text { [35] }\end{array}$ & RCS & + & + & + & + & \pm & \pm & - & - & + & - \\
\hline $\begin{array}{l}\text { Van Tetering } \\
\text { (2004) [7] }\end{array}$ & $\mathrm{RCT}$ & + & + & + & - & \pm & + & \pm & - & + & \pm \\
\hline $\begin{array}{l}\text { Westphal } \\
\text { (2004) [8] }\end{array}$ & $\mathrm{RCS}$ & + & + & + & + & \pm & + & + & - & - & \pm \\
\hline $\begin{array}{l}\text { Herscovici } \\
\text { (2005) [36] }\end{array}$ & RCS & \pm & + & + & + & \pm & - & \pm & - & + & - \\
\hline $\begin{array}{l}\text { Allmacher } \\
\text { (2006) [27] }\end{array}$ & RCS & + & + & + & - & \pm & \pm & - & - & - & - \\
\hline $\begin{array}{l}\text { Robb (2007) } \\
\text { [37] }\end{array}$ & $\mathrm{RCS}$ & + & + & + & - & - & + & \pm & - & + & - \\
\hline $\begin{array}{l}\text { Johal (2009) } \\
\text { [38] }\end{array}$ & $\mathrm{RCT}$ & + & + & + & - & + & + & \pm & - & - & \pm \\
\hline $\begin{array}{l}\text { Rubino } \\
\text { (2009) [28] }\end{array}$ & RCS & + & + & + & - & \pm & - & - & - & + & - \\
\hline $\begin{array}{l}\text { Wee (2009) } \\
\text { [39] }\end{array}$ & PCS & + & + & + & + & \pm & - & - & + & - & - \\
\hline $\begin{array}{l}\text { DeWall } \\
\text { (2010) [40] }\end{array}$ & RCS & + & + & + & - & + & \pm & - & - & - & - \\
\hline $\begin{array}{l}\text { Kinner (2010) } \\
\text { [41] }\end{array}$ & PCSS & + & + & + & + & \pm & + & NR & - & + & \pm \\
\hline $\begin{array}{l}\text { Makki (2010) } \\
\text { [6] }\end{array}$ & RCS & + & + & + & + & \pm & \pm & + & - & + & \pm \\
\hline $\begin{array}{l}\text { Hirschmüller } \\
\text { (2011) [42] }\end{array}$ & RCS & \pm & + & + & + & - & + & + & - & - & - \\
\hline $\begin{array}{l}\text { Tomesen } \\
\text { (2011) [43] }\end{array}$ & RCS & + & + & + & + & \pm & - & \pm & - & + & - \\
\hline $\begin{array}{l}\text { Woon (2011) } \\
\text { [44] }\end{array}$ & PCS & + & + & + & - & \pm & - & NR & - & - & - \\
\hline $\begin{array}{l}\text { Beltran } \\
\text { (2012) [45] }\end{array}$ & RCS & + & + & + & - & \pm & \pm & + & - & - & \pm \\
\hline $\begin{array}{l}\text { Brunner } \\
\text { (2012) [46] }\end{array}$ & RCS & + & + & + & - & \pm & + & \pm & - & + & \pm \\
\hline $\begin{array}{l}\text { Ågren (2013) } \\
\text { [47] }\end{array}$ & $\mathrm{RCT}$ & + & + & + & - & \pm & \pm & - & - & + & - \\
\hline $\begin{array}{l}\text { De Groot } \\
\text { (2013) [48] }\end{array}$ & RCS & + & + & + & - & \pm & + & - & - & + & \pm \\
\hline $\begin{array}{l}\text { Demiralp } \\
\text { (2013) [49] }\end{array}$ & RCS & \pm & + & + & - & - & - & NR & - & + & - \\
\hline $\begin{array}{l}\text { Kline (2013) } \\
\text { [50] }\end{array}$ & $\mathrm{RCS}$ & + & + & + & - & \pm & - & - & - & + & - \\
\hline \multirow{2}{*}{$\begin{array}{l}\text { Rammelt } \\
\text { (2013) [51] }\end{array}$} & $\mathrm{RCS}$ & + & + & + & - & + & \pm & - & - & - & - \\
\hline & PCS & \pm & + & + & - & - & \pm & NR & - & - & - \\
\hline
\end{tabular}


Table 3 Critical appraisal (see Table 2 for the legend) (Continued)

\begin{tabular}{|c|c|c|c|c|c|c|c|c|c|c|c|}
\hline \multicolumn{12}{|l|}{$\begin{array}{l}\text { Tornetta } \\
\text { (2013)[52] }\end{array}$} \\
\hline $\begin{array}{l}\text { Buckley } \\
\text { (2014) [53] }\end{array}$ & RCT & + & + & + & \pm & \pm & \pm & \pm & - & + & \pm \\
\hline $\begin{array}{l}\text { Chen (2014) } \\
\text { [54] }\end{array}$ & RCS & + & + & + & \pm & \pm & - & NR & - & + & - \\
\hline $\begin{array}{l}\text { De Boer } \\
\text { (2014) [55] }\end{array}$ & RCS & + & + & + & + & \pm & \pm & - & + & + & \pm \\
\hline $\begin{array}{l}\text { Griffin (2014) } \\
\text { [56] }\end{array}$ & RCT & + & + & + & + & \pm & \pm & \pm & + & + & \pm \\
\hline $\begin{array}{l}\text { Persson } \\
\text { (2014) [57] }\end{array}$ & RCS & \pm & + & + & + & \pm & \pm & - & - & + & - \\
\hline $\begin{array}{l}\text { Sanders } \\
\text { (2014) [58] }\end{array}$ & PCS & + & + & + & + & \pm & \pm & - & + & + & \pm \\
\hline
\end{tabular}

$R C T$ randomized controlled trial, $P C S$ prospective cohort study, $P C S S$ prospective cross sectional study, $R C S$ retrospective cohort study, NA not applicable, NR not reported

showed relatively low scores in the subdomains 'general health', 'vitality', and 'mental health', while the score in the subdomain 'role-emotional' was the highest of all studies.

The PCS and MCS are reported in six studies, of which only De Boer et al. [55] reported which reference population they used for calculating these scores $[6,45,53,56,58]$. Buckley et al. [53] reported just the PCS.

The mean EQ-5D index score was 0.69 in Griffin et al. [56], and the median EQ-5D index score in the study of De Boer et al. [55] was 0.78. The study of Griffin et al. [56] reported SF-36 MCS, SF-36 PCS and EQ-5D index score before and after trauma. The EQ-5D index showed a clinically significant decrease of the score with 0.21 points in patients with a DIACF. Also, the PCS and the MCS from the SF-36 survey decreased with respectively 11.9 and 2.0 points.

In one study, patients with DIACF are matched with a subject from the general population [8]. They are matched by age, gender, social state, comorbidity and place of residence. The results showed a statistically significant lower score in each subdomain for patients with DIACFs [8].

The data of the studies were not pooled because of a lack of homogeneity between studies; the studies have a great disparity in patient characteristics, type of fracture, treatment, and follow-up time [31].

Table 4 contains an overview of the subdomain scores, the studies are presented in order of follow-up time. The development of the scores through the years is graphically presented in the Appendix 1. The subdomain scores of 'bodily pain', 'general health', 'vitality', and 'role-physical' remained somewhat equal over time. The score of the 'social functioning', 'mental health', 'role-emotional', and 'physical functioning' increased over time.

\section{Discussion}

A DIACF is an injury known to cause impairments, which have a significant impact on a person's HRQoL, and on society and public health costs in terms of personal suffering and monetary losses.

Prior to this review we have observed numerous studies which evaluate the HRQoL. These studies tend to use different inclusion criteria and in particular observe specific patient groups. This might lead to skewed results and a misleading underestimation of the impact of a DIACF on the HRQoL. This in turn could limit the urge for improvements in the management of these fractures. We have performed this systematic review and aimed to evaluate the current literature on HRQoL in adult patients after sustaining a DIACF. This is the first systematic review that focuses solely on HRQoL after a DIACF.

This systematic review demonstrates that a lot of the studies have an increased risk of bias, mainly caused by the high lost to follow-up, selection bias and incomplete data reporting of patient and fracture characteristics. Moreover, this review shows that the SF-36 subdomains and the EQ-5D index scores are substantially lower in comparison to the period before the trauma and to the general population [46, 56, 59-63]. The results further present that the HRQoL after a DIACF is in particular affected in the subdomains related to the physical domain.

Several studies demonstrated scores in the SF-36 subdomains which were out of the range of the scores of the majority of the articles $[33,45,46,48]$. The lower scores of Beltran et al. [45] can be explained by the inclusion of only patients with high-grade open fractures. These patients have a more severe injury and are more likely to have worse outcomes. We were not able to clarify why the scores of the other studies deviated. Possible other factors, besides the DIACF, might have influenced the HRQoL, for instance socio-economic status or severity of fracture [33, 46, 48]. These factors were not always reported in these studies.

The designation of these studies is very challenging; the focus in these studies should be on decreasing the 
Table 4 Study population characteristics and SF-36 outcome results of selected studies

\begin{tabular}{|c|c|c|c|c|c|c|c|c|c|c|c|c|c|c|c|c|c|}
\hline & \multirow[t]{2}{*}{ Questionnaire } & \multirow{2}{*}{$\begin{array}{l}\text { Number of } \\
\text { patients }(n=)\end{array}$} & \multirow{2}{*}{$\begin{array}{l}\text { Reported } \\
\text { classification } \\
\text { of calcaneal } \\
\text { fracture type }\end{array}$} & \multirow{2}{*}{$\begin{array}{l}\text { Mean } \\
\text { age in } \\
\text { years } \\
\text { (range) }\end{array}$} & \multirow{2}{*}{$\begin{array}{l}\text { Other } \\
\text { characteristics } \\
\text { of studied } \\
\text { population }\end{array}$} & \multirow[t]{2}{*}{ Treatment } & \multirow{2}{*}{$\begin{array}{l}\text { Mean } \\
\text { follow-up } \\
\text { time in } \\
\text { months } \\
\text { (range) }\end{array}$} & \multicolumn{10}{|c|}{ SF-36 mean scores } \\
\hline & & & & & & & & $\begin{array}{l}\text { Physical } \\
\text { functioning }\end{array}$ & $\begin{array}{l}\text { Role- } \\
\text { physical }\end{array}$ & $\begin{array}{l}\text { Bodily } \\
\text { pain }\end{array}$ & $\begin{array}{l}\text { General } \\
\text { health }\end{array}$ & Vitality & $\begin{array}{l}\text { Social } \\
\text { functioning }\end{array}$ & $\begin{array}{l}\text { Role- } \\
\text { emotional }\end{array}$ & $\begin{array}{l}\text { Mental } \\
\text { health }\end{array}$ & $\begin{array}{l}\text { Physical } \\
\text { component } \\
\text { summary }\end{array}$ & $\begin{array}{l}\text { Mental } \\
\text { component } \\
\text { summary }\end{array}$ \\
\hline $\begin{array}{l}\text { Johal } \\
\text { (2009) } \\
{[38]}\end{array}$ & SF-36 & 41 & Sanders & $\begin{array}{l}36 \\
(18-61)\end{array}$ & $\begin{array}{l}\text { Exclusion of open } \\
\text { fractures, aged } \\
>65 \text { years, } \\
\text { medical } \\
\text { contraindications } \\
\text { or intoxication } \\
\text { abuses }\end{array}$ & ORIF & $>12$ (NR) & 59 & 40 & 51 & 77 & 63 & 67 & 65 & 74 & - & - \\
\hline $\begin{array}{l}\text { Van } \\
\text { Tetering } \\
\text { (2004) [7] }\end{array}$ & SF-36 & 312 & NR & $\begin{array}{l}\text { NR } \\
(25-64)\end{array}$ & $\begin{array}{l}\text { Exclusion of } \\
\text { open fractures } \\
\text { and age }<25 \text { and } \\
>65 \text { years. } \\
\text { Possible } \\
\text { exclusion of } \\
\text { patients who } \\
\text { received } \\
\text { secondary } \\
\text { subtalar } \\
\text { arthrodesis }\end{array}$ & $\begin{array}{l}\text { ORIF or } \\
\text { non-operative }\end{array}$ & $\begin{array}{l}23 \\
(12-24)\end{array}$ & 67 (SD 27) & $\begin{array}{l}54(S D \\
43)\end{array}$ & 57 (SD 26) & $\begin{array}{l}69 \\
\text { (SD 20) }\end{array}$ & $\begin{array}{l}60 \\
\text { (SD 21) }\end{array}$ & 73 (SD 27) & $\begin{array}{l}72 \\
\text { (SD 38) }\end{array}$ & $\begin{array}{l}72 \\
\text { (SD 19) }\end{array}$ & - & - \\
\hline $\begin{array}{l}\text { Griffin } \\
(2014) \\
{[56]}\end{array}$ & SF-36 & 116 & Sanders & $\begin{array}{l}47 \\
(18-80)\end{array}$ & $\begin{array}{l}\text { Exclusion of } \\
\text { open fractures, } \\
\text { gross deformity, } \\
\text { other serious leg } \\
\text { injury or } \\
\text { peripheral } \\
\text { vascular disease }\end{array}$ & $\begin{array}{l}\text { Operative } \\
(n=62), \\
\text { non-operative } \\
(n=54)\end{array}$ & 24 (NR) & - & - & - & - & - & & - & - & $40^{C}(S D$ 13) & $54^{c}(\mathrm{SD} 12)$ \\
\hline $\begin{array}{l}\text { Buckley } \\
\text { (2014) } \\
{[53]}\end{array}$ & $\begin{array}{l}\text { SF-36 version } \\
2\end{array}$ & 24 & Sanders & $\begin{array}{l}40 \\
\text { (SD 13) }\end{array}$ & $\begin{array}{l}\text { Closed Sanders } \\
\text { type IV fractures; } \\
\text { exclusion age } \\
<16 \text { and } \\
>59 \text { years, } \\
\text { inability of } \\
\text { diminishing } \\
\text { smoking after } \\
\text { injury }\end{array}$ & $\begin{array}{l}\text { ORIF }(n=11), \\
\text { ORIF and } \\
\text { primary } \\
\text { arthrodesis } \\
(n=13)\end{array}$ & $\begin{array}{l}\geq 24 \\
(24-84)\end{array}$ & & - & - & - & & & & - & $34^{c}(S D$ 11) & - \\
\hline $\begin{array}{l}\text { Heffernan } \\
\text { (2000) } \\
{[33]}\end{array}$ & SF-36 & 25 & NR & $\begin{array}{l}44 \\
(22-65) \\
\text { at time } \\
\text { of injury }\end{array}$ & - & ORIF & $\begin{array}{l}30 \\
(12-48)\end{array}$ & $\begin{array}{l}\text { Median83 } \\
\text { (range } \\
70-100 \text { ) }\end{array}$ & - & $\begin{array}{l}\text { Median84 } \\
\text { (range } \\
27-100)\end{array}$ & - & - & - & - & - & - & - \\
\hline $\begin{array}{l}\text { Westphal } \\
\text { (2004) [8] }\end{array}$ & SF-36 & 71 & Sanders & $\begin{array}{l}42 \\
(22-73) \\
\text { at time } \\
\text { of injury }\end{array}$ & $\begin{array}{l}\text { Exclusion of } \\
\text { bilateral or open } \\
\text { fractures, or } \\
\text { having other } \\
\text { injuries }\end{array}$ & $\begin{array}{l}\text { ORIF, } \\
\text { secondary } \\
\text { arthrodesis } \\
(n=4)\end{array}$ & $\begin{array}{l}32 \\
(11-90)\end{array}$ & 61 (SD 25) & $\begin{array}{l}52(S D \\
43)\end{array}$ & 49 (SD 27) & $\begin{array}{l}58 \\
\text { (SD 20) }\end{array}$ & $\begin{array}{l}56 \\
\text { (SD 20) }\end{array}$ & 79 (SD 23) & $\begin{array}{l}74 \\
\text { (SD 40) }\end{array}$ & $\begin{array}{l}69 \\
\text { (SD 21) }\end{array}$ & - & - \\
\hline $\begin{array}{l}\text { Brunner } \\
(2012) \\
{[46]}\end{array}$ & SF-36 & 54 & OTA & NR & $\begin{array}{l}\text { Exclusion of } \\
\text { other fixation } \\
\text { systems }\end{array}$ & ORIF & $\begin{array}{l}42 \\
(24-82)\end{array}$ & 62 & 68 & 53 & 43 & 49 & 83 & 90 & 41 & - & - \\
\hline $\begin{array}{l}\text { Kinner } \\
(2010) \\
{[41]}\end{array}$ & SF-36 & 44 & Sanders & $\begin{array}{l}46 \\
(18-65)\end{array}$ & $\begin{array}{l}\text { Complete } \\
\text { clinical and } \\
\text { radiographic }\end{array}$ & $\begin{array}{l}\text { ORIF }(n=32), \\
\text { percutaneous } \\
(n=12)\end{array}$ & $\begin{array}{l}42 \\
(12-60)\end{array}$ & 66 & 66 & 58 & 64 & 60 & 81 & 79 & 76 & - & - \\
\hline
\end{tabular}


Table 4 Study population characteristics and SF-36 outcome results of selected studies (Continued)

\begin{tabular}{|c|c|c|c|c|c|c|c|c|c|c|c|c|c|c|c|c|c|}
\hline & & & & & $\begin{array}{l}\text { documentation. } \\
\text { Exclusion aged } \\
<65 \text {. }\end{array}$ & & & & & & & & & & & & \\
\hline $\begin{array}{l}\text { Beltran } \\
(2012) \\
{[45]}\end{array}$ & SF-36 & 15 & Sanders & $\begin{array}{l}43 \\
(16-67)\end{array}$ & $\begin{array}{l}\text { High-grade } \\
\text { open calcaneal } \\
\text { fractures only }\end{array}$ & Percutaneous & $\begin{array}{l}49 \\
(13-106)\end{array}$ & 40 (SD 13) & $\begin{array}{l}43(S D \\
16)\end{array}$ & 48 (SD 10) & $\begin{array}{l}52 \\
\text { (SD 8) }\end{array}$ & $\begin{array}{l}48 \\
\text { (SD 10) }\end{array}$ & 44 (SD 10) & - & - & $44^{c}(S D 12)$ & $49^{\mathrm{C}}(\mathrm{SD} 13)$ \\
\hline $\begin{array}{l}\text { De Boer } \\
\text { (2014) } \\
{[55]}\end{array}$ & SF-36 & 78 & $\begin{array}{l}\text { Sanders/ } \\
\text { Essex- } \\
\text { Lopresti }\end{array}$ & $\begin{array}{l}46 \\
\text { (30-55) } \\
\text { at time } \\
\text { of injury }\end{array}$ & $\begin{array}{l}\text { Exclusion of age } \\
>70, \text { primary } \\
\text { arthrodesis or } \\
\text { amputation, } \\
\text { Gustilo grade III, } \\
\text { intoxication } \\
\text { abuses or } \\
\text { wheelchair- } \\
\text { bound. }\end{array}$ & $\begin{array}{l}\text { ORIF }(n=27), \\
\text { non-operative } \\
(n=18) \\
\text { percutaneous } \\
(n=33)\end{array}$ & $\begin{array}{l}76 \\
(54-88)\end{array}$ & - & - & - & - & - & - & - & - & $\begin{array}{l}\text { Median } \\
48^{\mathrm{a}}\end{array}$ & $\begin{array}{l}\text { Median } \\
57^{\mathrm{a}}\end{array}$ \\
\hline $\begin{array}{l}\text { De Groot } \\
\text { (2013) } \\
{[48]}\end{array}$ & SF-36 & 41 & NR & $\begin{array}{l}46 \\
(\text { SD 11) } \\
(21-66)\end{array}$ & $\begin{array}{l}\text { Exclusion of } \\
\text { open fractures, } \\
\text { severe mental } \\
\text { illness or do not } \\
\text { reside nearby }\end{array}$ & $\begin{array}{l}\text { ORIF }(n=39) \\
\text { unknown } \\
(n=2)\end{array}$ & $\begin{array}{l}78 \\
(24-192)\end{array}$ & 74 (SD 21) & $\begin{array}{l}65(S D \\
41)\end{array}$ & 71 (SD 22) & $\begin{array}{l}70 \\
\text { (SD 19) }\end{array}$ & $\begin{array}{l}70 \\
\text { (SD 20) }\end{array}$ & 85 (SD 22) & $\begin{array}{l}81 \\
\text { (SD 35) }\end{array}$ & $\begin{array}{l}79 \\
\text { (SD 20) }\end{array}$ & - & - \\
\hline $\begin{array}{l}\text { Makki } \\
\text { (2010) } \\
{[6]}\end{array}$ & $\begin{array}{l}\text { SF-36 version } \\
2\end{array}$ & 41 & Sanders & $\begin{array}{l}56 \\
\text { (27-85) } \\
\text { at time } \\
\text { of follow- } \\
\text { up }\end{array}$ & $\begin{array}{l}\text { Exclusion of } \\
\text { comminution of } \\
\text { sustentacular } \\
\text { fragment; open } \\
\text { fractures; } \\
\text { exclusion of } \\
\text { secondary } \\
\text { arthrodesis }\end{array}$ & ORIF & $\begin{array}{l}120 \\
(84-180)\end{array}$ & - & - & - & - & - & - & - & - & $50^{\mathrm{bc}}(\mathrm{SD} 7)$ & $54^{\mathrm{bc}}(\mathrm{SD} 4)$ \\
\hline $\begin{array}{l}\text { Sanders } \\
\text { (2014) } \\
\text { [58] }\end{array}$ & $\begin{array}{l}\text { SF-36 version } \\
2\end{array}$ & 66 & $\begin{array}{l}\text { Sanders/ } \\
\text { Essex- } \\
\text { Lopresti }\end{array}$ & $\begin{array}{l}60 \\
\text { (SD 15) } \\
\text { (29-91) } \\
\text { at time } \\
\text { of follow- } \\
\text { up }\end{array}$ & $\begin{array}{l}\text { Exclusion of } \\
\text { open fractures, } \\
\text { concomitant } \\
\text { injuries, } \\
\text { incomplete } \\
\text { radiographic } \\
\text { documentation, } \\
\text { Sanders type IV, } \\
\text { unsuited for } \\
\text { operative } \\
\text { treatment or } \\
\text { subtalar fusion }\end{array}$ & ORIF & $\begin{array}{l}181 \\
(126-256)\end{array}$ & - & - & - & - & - & - & - & - & $46^{c}(S D 9)$ & $55^{c}(\mathrm{SD} 11)$ \\
\hline
\end{tabular}

ORIF open reduction, internal fixation, $N R$ not reported, $S D=$ standard deviation

a Norm based scoring weighed upon the United States general population (1998) [71]; ${ }^{b}$ Norm based scoring: mean 50 (SD 10); ${ }^{c}$ Not reported how it was calculated 
risk of bias. The following suggestions might decrease the risk of bias and benefit future research. Patients who sustained a DIACF are considered to be a group who are difficult to follow-up. Nonetheless, all the studies with a medium risk of bias have a decent follow-up of $75 \%$ or better. To increase the follow-up rate in future studies; it may be worthwhile to use a shorter questionnaire (e.g. EQ-5D). In addition, we recommend that patient and fracture characteristics of the eligible population are reported to interpret the bias caused by loss to follow-up.

Furthermore, we suggest that future studies include data regarding factors that influence HRQoL, such as socioeconomic status, acceptability of the disease in the population, and the quality of health care $[60,64,65]$. Also data of certain patient and injury characteristics, e.g. age, concomitant injuries, and classification of calcaneal fracture, are important to report because these factors influence HRQoL substantially [28]. Adding this information in these studies increases the generalizability and applicability to other study populations and the individual patient.

We have demonstrated in the critical appraisal (Table 3) that the majority of the studies had a selection bias. These studies excluded patients with open or bilateral fractures, multiple injured patients, patients who received secondary subtalar arthrodesis ('failure' of treatment), and patients who were not eligible for a certain treatment (Table 3). It is likely that these patients have worse HRQoL outcome compared to patients with an isolated and closed DIACF. Therefore, the results may be distorted and the impact on the HRQoL might be even worse than presented in this review. Thus, ideally, future studies include all type of patients and fractures, and all their characteristics should be reported as discussed above.

The development of the subdomain scores over time (Table 4 and Appendix 1) shows that 'social functioning', 'physical functioning', 'mental health', and 'role-emotional' improve over time. This could indicate that the rehabilitation period for this injury is a very time-consuming process or that patients learn to cope with their limitations. Given the changes in HRQoL over time, we might suggest that it is important to measure HRQoL during a long follow-up period.

Several studies in our review only reported the SF-36 PCS and MCS results. These scores are useful to summarize the HRQoL. Though, some studies demonstrated that these summarized scores possibly do not reflect accurately the HRQoL in comparison to the scores per subdomain $[66,67]$. Moreover, an advantage of the scores per subdomain is the possibility to compare the survey with other surveys, such as the Maryland Foot Score, AOFAS Ankle Hindfoot Scale, and Iowa Calcaneal Score or to combine the result in a meta-analysis [8, 27, 33, 52, 67-70].

The significantly decrease in HRQoL indicates that a DIACF is a life-changing event, regardless of HRQoL status before the DIACF, type of fracture, nonoperative or operative treatment, or additional injuries. It has a great impact on a person's physical and social function.

The considerable loss in HRQoL shows the need for advancements in the management strategy of a DIACF in order to improve functional outcome. In current literature there is no consensus yet what the best treatment of these patients should be. A recently published randomized controlled trial demonstrated that there actually is no difference in subjective and objective outcomes after two years between non-operative and operative treatment of DIACF. [56] Although operative treatment is considered the gold standard nowadays in treatment of DIACF, this study suggests that patients who were operatively treated could still endure a severe loss in their HRQoL. Apart from the treatment of a fracture, other management strategies may be introduced. Physical functioning might be improved by early involvement of the rehabilitation physician, and psychotherapy might be helpful to cope with potentially impaired mental functioning after a trauma that caused a DIACF.

In conclusion, this systematic review indicates that DIACF is a life-changing event for most patients. However, we should be careful to deduct definite conclusions; we revealed that the identified studies have a medium to high risk of bias that might cause underestimation of the HRQoL after a DIACF. Thus, it is challenging to make reliable and valid conclusions.

In future, we recommend that research aims to decrease risk of bias. Ideally, future studies on HRQoL should use shorter questionnaires to aim for a higher follow-up rate, present data on the patients which were not included, and preferably include all patients with DIACF despite their characteristics which likely influence the HRQoL outcome negatively. Furthermore, it would be useful to present all relevant patient characteristics and injury characteristics. All of this is necessary to lower the risk of bias as best as possible in this challenging population; in order to interpret the results better and to create a more representative, inclusive image on the consequences on the daily lives of patients who endured a DIACF.

\section{Conclusions}

- This systematic review reveals that the identified studies have a medium to high risk of bias that might cause underestimation of the HRQoL after a DIACF; hence, it is challenging to make reliable and valid conclusions.

- This systematic review indicates that DIACF is a life-changing event for most patients. 


\section{Appendix 1}
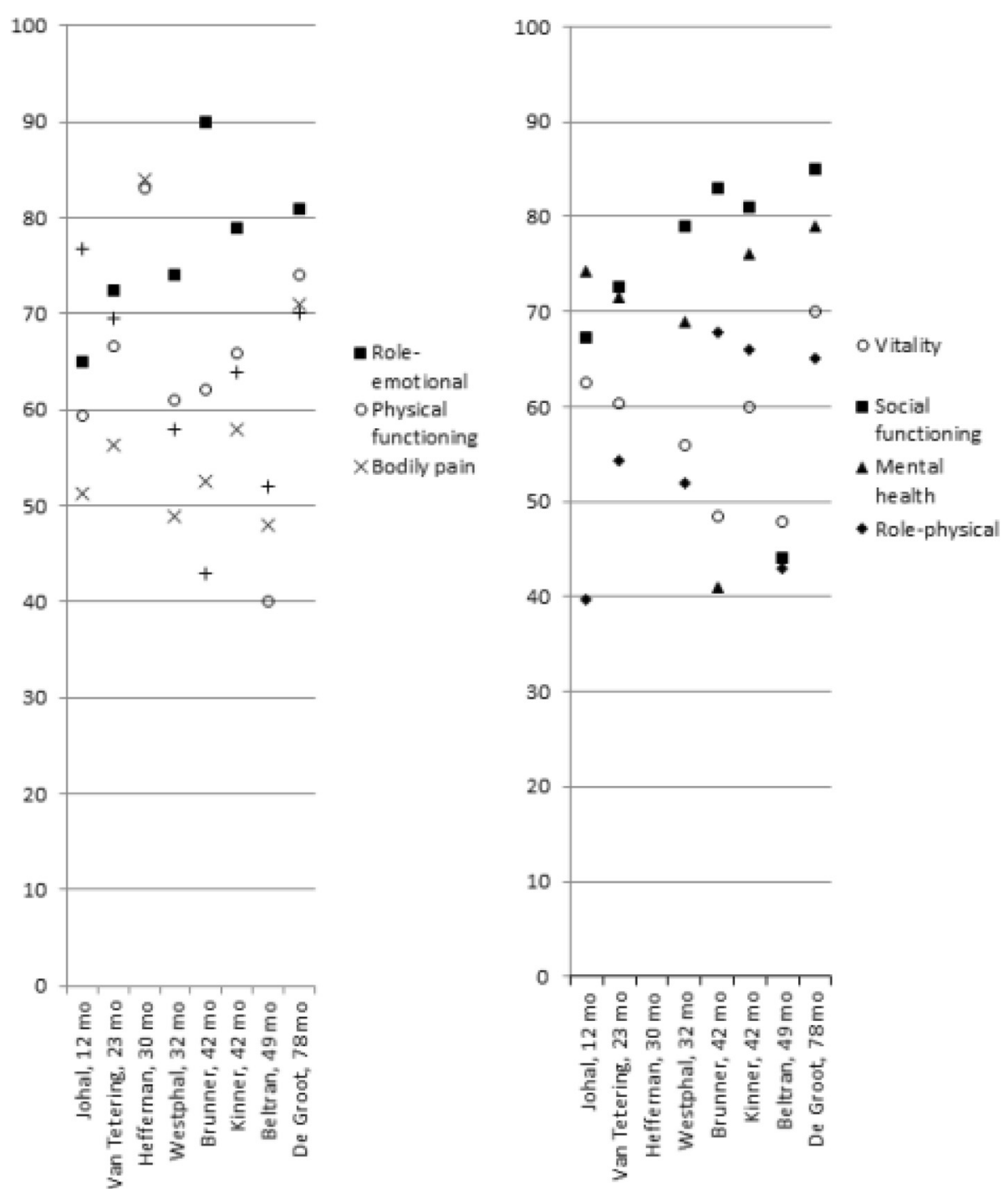

Fig. 2 A The SF-36 subdomain scores development in time 


\section{Abbreviations}

ACG: Amy Gunning; DIACF: Displaced intra-articular calcaneal fracture; EQ-5D: EuroQol 5D; EQ-6D: EuroQol 6D; GA: Georgios Alexandridis; HRQoL: Health-related quality of life; LPHL: Luke Leenen; MCS: Mental component summary; OTA: Orthopaedic Trauma Association; PCS: Physical component summary; PRISMA: Preferred Reporting Items for Systematic Reviews and Meta-Analyses; SF-36: Medical Outcomes Study 36-item Short Form Health Survey; SF-36v2: Medical Outcomes Study 36-item Short Form Health Survey version 2.0.

\section{Competing interests}

The authors declare no conflict of interests.

\section{Authors' contributions}

GA: created the search syntax, performed the initial search and title/abstract screening, in-depth screening, critical appraisement, extracted the results and writer of article. ACG: in-depth screening, creator and performer of the critical appraisement and reviser of article. LPHL: supervisor, reviser of article, input on creation reasons and discussion companion. All authors read and approved the final manuscript.

\section{Received: 22 September 2015 Accepted: 21 December 2015}

\section{Published online: 30 December 2015}

\section{References}

1. Buckley R, Tough S, McCormack R, Pate G, Leighton R, Petrie D, et al. Operative compared with nonoperative treatment of displaced intraarticular calcaneal fractures: a prospective, randomized, controlled multicenter trial. J Bone Joint Surg Am. 2002;84-A(10):1733-44.

2. Pozo JLL, Kirwan EO, Jackson AM. The long-term results of conservative management of severely displaced fractures of the calcaneus. J Bone Joint Surg Br. 1984;66(3):386-90.

3. Button G, Pinney S. A meta-analysis of outcome rating scales in foot and ankle surgery: is there a valid, reliable, and responsive system? Foot Ankle Int. 2004;25(8):521-5

4. Madeley NJ, Wing KJ, Topliss C, Penner MJ, Glazebrook MA, Younger AS. Responsiveness and validity of the

SF-36, Ankle Osteoarthritis Scale, AOFAS Ankle Hindfoot Score, and Foot Function Index in end stage ankle arthritis. Foot Ankle Int. 2012;33(1):57-63.

5. SooHoo NF, Vyas R, Samimi D. Responsiveness of the foot function index, AOFAS clinical rating systems, and SF-36 after foot and ankle surgery. Foot Ankle Int. 2006;27(11):930-4

6. Makki D, Alnajjar HM, Walkay S, Ramkumar U, Watson AJ, Allen PW. Osteosynthesis of displaced intra-articular fractures of the calcaneum: a long-term review of 47 cases. J Bone Joint Surg Br. 2010;92(5):693-700.

7. Van Tetering EA, Buckley RE. Functional outcome (SF-36) of patients with displaced calcaneal fractures compared to SF-36 normative data. Foot Ankle Int. 2004:25(10):733-8.

8. Westphal T, Piatek S, Halm JP, Schubert S, Winckler S. Outcome of surgically treated intraarticular calcaneus fractures-SF-36 compared with AOFAS and MFS. Acta Orthop Scand. 2004;75(6):750-5.

9. Bajammal S, Tornetta P 3rd, Sanders D, Bhandari M. Displaced intra-articular calcaneal fractures. J Orthop Trauma. 2005;19(5):360-4.

10. Bridgman SA, Dunn KM, McBride DJ, Richards PJ. Interventions for treating calcaneal fractures. Cochrane Database Syst Rev. 2000;2:CD001161.

11. Bridgman S1, Dunn K, McBride D, Richards P. Withdrawn: Interventions for treating calcaneal fractures. Cochrane Database Syst Rev. 2008;4:CD001161.

12. Bondi R, Padua R, Bondi L, Battaglia A, Romanini E, Campi A. Treatment of calcaneal fractures: The available evidence. J Orthopaed Traumatol. 2007; 8(1):36-41.

13. Bruce J, Sutherland A. Surgical versus conservative interventions for displaced intra-articular calcaneal fractures. Cochrane Database Syst Rev. 2013;1:CD008628.

14. Gougoulias N1, Khanna A, McBride DJ, Maffulli N. Management of calcaneal fractures: Systematic review of randomized trials. Br Med Bull. 2009;92(1):153-67.

15. Jiang $N$, Lin QR, Diao XC, Wu L, Yu B. Surgical versus nonsurgical treatment of displaced intra-articular calcaneal fracture: a meta-analysis of current evidence base. Int Orthop. 2012;36(8):1615-22.

16. Randle JA, Kreder HJ, Stephen D, Williams J, Jaglal S, Hu R. Should calcaneal fractures be treated surgically? A meta-analysis. Clin Orthop Relat Res. 2000; 377:217-27.
17. Veltman ES, Doornberg JN, Stufkens SA, Luitse JS, van den Bekerom MP. Long-Term Outcomes of 1,730 Calcaneal Fractures: Systematic Review of the Literature. J Foot Ankle Surg. 2013;52(4):486-90

18. Moher D, Liberati A, Tetzlaff J, Altman DG; PRISMA Group. Preferred Reporting items for systematic reviews and meta-analyses: the PRISMA statement. BMJ. 2009;339:b2535.

19. Krabbe PF, Stouthard ME, Essink-Bot ML, Bonsel GJ. The effect of adding a cognitive dimension to the EuroQol multiattribute health-status classification system. J Clin Epidemiol. 1999;52(4):293-301.

20. Williams A. EuroQol - A new facility for the measurement of health-related quality of life. Health Policy. 1990;16(3):199-208.

21. Ware Jr JE, The SCD, MOS. 36-item short-form health survey (SF-36). I. Conceptual framework and item selection. Med Care. 1992;30(6):473-83.

22. Ware JE, Kosinski M, Dewey JE. How to Score Version Two of the SF-36 Health Survey. Lincoln: QualityMetric, Incorporated; 2000.

23. Centre for Evidence-Based Medicine (2014) http://www.cebm.net/?o=1913 Accessed 16 March 2014

24. Filbay SR, Ackerman IN, Russell TG, Macri EM, Crossley KM. Health-related quality of life after anterior cruciate ligament reconstruction: a systematic review. Am J Sports Med. 2014;42(5):1247-55.

25. Van Son MA1, De Vries J, Roukema JA, Den Oudsten BL. Health status, health-related quality of life, and quality of life following ankle fractures: a systematic review. Injury. 2013:44(11):1391-402.

26. Winters ZE, Benson JR, Pusic AL. A systematic review of the clinical evidence to guide treatment recommendations in breast reconstruction based on patient- reported outcome measures and health-related quality of life. Ann Surg. 2010;252(6):929-42.

27. Allmacher DH, Galles KS, Marsh JL. Intra-articular calcaneal fractures treated nonoperatively and followed sequentially for 2 decades. J Orthop Trauma. 2006;20(7):464-9.

28. Rubino R, Valderrabano V, Sutter PM, Regazzoni P. Prognostic value of four classifications of calcaneal fractures. Foot Ankle Int. 2009:30(3):229-38.

29. Higgins JPT, Green S. Cochrane Handbook for Systematic Reviews of Interventions Version 5.1.0 [updated March 2011]. http://handbook.cochrane. org/chapter_8/8_2_2_risk_of_bias_and_quality.htm. Accessed 18 March 2014.

30. Ware Jr JE. SF-36 Health Survey Update. Spine (Phila Pa 1976). 2000;25(24): 3130-9.

31. Opstelten W, Scholten RJ. Meta-analysis: principles and pitfalls. Ned Tijdschr Geneeskd. 2014;158(6):A6882.

32. Hildebrand KA, Buckley RE, Mohtadi NG, Faris P. Functional outcome measures after displaced intra-articular calcaneal fractures. J Bone Joint Surg Br. 1996;78(1):119-23.

33. Heffernan G, Khan F, Awan N, Riordain CO, Corrigan J. A comparison of outcome scores in os calcis fractures. Ir J Med Sci. 2000;169(2):127-8.

34. Kennedy JG, Jan WM, McGuinness AJ, Barry K, Curtin J, Cashman WF, et al. An outcomes assessment of intra-articular calcaneal fractures, using patient and physician's assessment profiles. Injury. 2003;34(12):932-6.

35. Berry GK, Stevens DG, Kreder HJ, McKee M, Schemitsch E, Stephen DJ. Open fractures of the calcaneus: a review of treatment and outcome. J Orthop Trauma. 2004;18(4):202-6.

36. Herscovici D Jr, Widmaier J, Scaduto JM, Sanders RW, Walling A. Operative treatment of calcaneal fractures in elderly patients. J Bone Joint Surg Am. 2005:87(6):1260-4

37. Robb CA, Deans V, Iqbal MJ, Cooper JP. Comparison of non-operative and surgical treatment of displaced calcaneal fractures. Foot. 2007;17(4):169-73.

38. Johal HS, Buckley RE, Le IL, Leighton RK. A prospective randomized controlled trial of a bioresorbable calcium phosphate paste (alpha-BSM) in treatment of displaced intra-articular calcaneal fractures. J Trauma. 2009; 67(4):875-82

39. Wee AT, Wong YS. Percutaneous reduction and injection of Norian bone cement for the treatment of displaced intra-articular calcaneal fractures. Foot Ankle Spec. 2009:2(2):98-106.

40. DeWall M, Henderson CE, McKinley TO, Phelps T, Dolan L, Marsh JL. Percutaneous reduction and fixation of displaced intra-articular calcaneus fractures. J Orthop Trauma. 2010;24(8):466-72.

41. Kinner B, Schieder S, Müller F, Pannek A, Roll C. Calcaneocuboid joint involvement in calcaneal fractures. J Trauma. 2010;68(5):1192-9.

42. Hirschmüller A, Konstantinidis L, Baur H, Müller S, Mehlhorn A, Kontermann $J$, et al. Do changes in dynamic plantar pressure distribution, strength capacity and postural control after intra-articular calcaneal fracture correlate with clinical and radiological outcome? Injury. 2011;42(10):1135-43. 
43. Tomesen T, Biert J, Frölke JP. Treatment of displaced intra-articular calcaneal fractures with closed reduction and percutaneous screw fixation. J Bone Joint Surg Am. 2011;93(10):920-8.

44. Woon CY, Chong KW, Yeo W, Eng-Meng Yeo N, Wong MK. Subtalar arthroscopy and flurosocopy in percutaneous fixation of intra-articular calcaneal fractures: the best of both worlds. J Trauma. 2011;71(4):917-25.

45. Beltran MJ, Collinge CA. Outcomes of high-grade open calcaneus fractures managed with open reduction via the medial wound and percutaneous screw fixation. J Orthop Trauma. 2012;26(11):662-70.

46. Brunner A, Müller J, Regazzoni P, Babst R. Open reduction and internal fixation of OTA type C2-C4 fractures of the calcaneus with a triple-plate technique. J Foot Ankle Surg. 2012;51(3):299-307.

47. Agren PH, Wretenberg P, Sayed-Noor AS. Operative versus nonoperative treatment of displaced intra-articular calcaneal fractures: a prospective, randomized, controlled multicenter trial. J Bone Joint Surg Am. 2013;95(15):1351-7.

48. De Groot R, Frima AJ, Schepers T, Roerdink WH. Complications following the extended lateral approach for calcaneal fractures do not influence $<$ ?show [?A3B2 show \$9\#?]?> mid- to long-term outcome. Injury. 2013;44(11):1596-600.

49. Demiralp B, Ege T, Kose O, Yurttas Y, Basbozkurt M. Amputation versus functional reconstruction in the management of complex hind foot injuries caused by land-mine explosions: a long-term retrospective comparison. Eur J Orthop Surg Traumatol. 2014;24(4):621-6.

50. Kline AJ, Anderson RB, Davis WH, Jones CP, Cohen BE. Minimally invasive technique versus an extensile lateral approach for intra-articular calcaneal fractures. Foot Ankle Int. 2013;34(6):773-80.

51. Rammelt S, Zwipp H, Schneiders W, Dürr C. Severity of injury predicts subsequent function in surgically treated displaced intraarticular calcaneal fractures. Clin Orthop Relat Res. 2013;471(9):2885-98.

52. Tornetta 3rd P, Qadir R, Sanders R. Pain Dominates Summed Scores for Hindfoot and Ankle Trauma. J Orthop Trauma. 2013;27(8):477-82.

53. Buckley R, Leighton R, Sanders D, Poon J, Coles CP, Stephen D, et al. Open reduction and internal fixation compared with ORIF and primary subtalar arthrodesis for treatment of Sanders type IV calcaneal fractures: a randomized multicenter trial. J Orthop Trauma. 2014;28(10):577-83.

54. Chen K, Zhang H, Wang G, Cheng Y, Qian Z, Yang H. Comparison of nonlocking plates and locking plates for intraarticular calcaneal fracture. Foot Ankle Int. 2014;35(12):1298-302.

55. De Boer AS, Van Lieshout EM, Den Hartog D, Weerts B, Verhofstad MH, Schepers T. Functional outcome and patient satisfaction after displaced intra-articular calcanealfractures: a comparison among open, percutaneous, and nonoperative treatment. J Foot Ankle Surg. 2015;54(3):298-305.

56. Griffin D, Parsons N, Shaw E, Kulikov Y, Hutchinson C, Thorogood M, et al. Operative versus non-operative treatment for closed, displaced, intra-articular fractures of the calcaneus: randomised controlled trial. BMJ. 2014;349:g4483.

57. Persson J, Peters S, Haddadin S, O'Loughlin PF, Krettek C, Gaulke R. The prognostic value of radiologic parameters for long-term outcome assessment after an isolated unilateral calcaneus fracture. Technol Health Care. 2015;23(3):285-98.

58. Sanders R, Vaupel Z, Erdogan M, Downes K. The Operative Treatment of Displaced Intra-articular Calcaneal Fractures (DIACFs): Long Term (10-20 years) Results in 108 Fractures using a Prognostic CT Classification. J Orthop Trauma. 2014;jun 30.

59. Brink E, Grankvist G, Karlson BW, Hallberg LR. Health-related quality of life in women and men one year after acute myocardial infarction. Qual Life Res. 2005;14(3):749-57.

60. Hoeymans N, van Lindert H, Westert GP. The health status of the Dutch population as assessed by the EQ-6D. Qual Life Res. 2005;14(3):655-63.

61. Hopman WM, Towheed T, Anastassiades T, Tenenhouse A, Poliquin S, Berger C, et al. Canadian normative data for the SF-36 health survey. Canadian Multicentre Osteoporosis Study Research Group. CMAJ. 2000; 163(3):265-71.

62. Jenkinson C, Stewart-Brown S, Petersen S, Paice C. Assessment of the SF-36 version 2 in the United Kingdom. J Epidemiol Community Health. 1999; 53(1):46-50

63. Kind P, Dolan P, Gudex C, Williams A. Variations in population health status: results from a United Kingdom national questionnaire survey. BMJ. 1998; 316:736-41.

64. Gandek B, Ware JE, Aaronson NK, Apolone G, Bjorner JB, Brazier JE, et al. Crossvalidation of item selection and scoring for the SF-12 Health Survey in nine countries: Results from the IQOLA Project. J Clin Epidemiol. 1998;51:1171-8.
65. Loge JH, Kaasa S. Short Form 36 (SF-36) health survey: normative data from the general Norwegian population. Scand J Soc Med. 1998;26:250-8.

66. Taft C, Karlsson J, Sullivan M. Do SF-36 summary component scores accurately summarize subscale scores? Qual Life Res. 2001;10(5):395-404.

67. Ware JE, Kosinski M. Interpreting SF-36 summary health measures: a response. Qual Life Res. 2001;10(5):405-13. discussion 415-20.

68. Kitaoka HB, Alexander IJ, Adelaar RS, Nunley JA, Myerson MS, Sanders M. Clinical rating systems for the ankle-hindfoot, midfoot, hallux, and lesser toes. Foot Ankle Int. 1994;15(7):349-53.

69. Myerson MS, Fisher RT, Burgess AR, Kenzora JE. Fracture dislocations of the tarsometatarsal joints: end results correlated with pathology and treatment. Foot Ankle. 1986;6:225-42.

70. Westphal T, Halm JP, Piatek S, Schubert S, Winckler S. Quality of life after calcaneal fractures. A matched-pairs trial with a standardised German control group. Unfallchirurg. 2003;106(4):313-8.

71. Aaronson NK, Muller M, Cohen PD, Essink-Bot ML, Fekkes M, Sanderman R, et al. Translation, validation, and norming of the Dutch language version of the SF-36 Health Survey in community and chronic disease populations. J Clin Epidemiol. 1998;51(11):1055-68.

\section{Submit your next manuscript to BioMed Central and we will help you at every step:}

- We accept pre-submission inquiries

- Our selector tool helps you to find the most relevant journal

- We provide round the clock customer support

- Convenient online submission

- Thorough peer review

- Inclusion in PubMed and all major indexing services

- Maximum visibility for your research

Submit your manuscript at www.biomedcentral.com/submit
) Biomed Central 